Revue d'histoire de l'enfance « irrégulière »

Le Temps de l'histoire

$10 \mid 2008$

La prostitution des mineur(e)s au $\mathrm{XX}^{\mathrm{e}}$ siècle

\title{
Pour une histoire des maisons d'enfants
}

Comité de rédaction

\section{(2) OpenEdition}

Journals

Édition électronique

URL : http://journals.openedition.org/rhei/2967

DOI : 10.4000/rhei.2967

ISBN : 978-2-7535-1649-6

ISSN : 1777-540X

Éditeur

Presses universitaires de Rennes

Édition imprimée

Date de publication : 1 octobre 2008

Pagination : 159

ISSN : 1287-2431

Référence électronique

Comité de rédaction, "Pour une histoire des maisons d'enfants », Revue d'histoire de l'enfance " irrégulière » [En ligne], 10 | 2008, mis en ligne le 01 octobre 2008, consulté le 04 décembre 2020. URL http://journals.openedition.org/rhei/2967 ; DOI : https://doi.org/10.4000/rhei.2967 


\section{Pour une histoire des maisons d'enfants}

Dans sa participation à l'ouvrage collectif sur Les maisons d'enfants, édité par les Presses universitaires de France en I950, Alfred Brauner (1) évoque l'" extension endémique " des communautés d'enfants depuis la dernière guerre, "en baptisant à tort et à travers leur entreprise tantôt cité, tantôt république ", ou bien encore "village d'enfants". Il sinquiète en particulier de l'usage généralisé de ce qu'il appelle des méthodes factices : "self government des enfants", "monnaie intérieure ", " tribunal d'enfants", avec "conseil municipal ", "petit maire de quatorze ans avec écharpe tricolore ", caricaturant la société des adultes.

Sa dénonciation se fait d'autant plus vive qu'il pointe que toutes ces initiatives se font en "vase clos et que la meilleure astuce pédagogique ne remplace pas le monde réel ". (2) Ce cri d'alarme lancé il y a à peine soixante ans nous laisse aujourd'hui perplexe tant ces expériences originales semblent avoir laissé peu de traces. À l'exception d'un usage récent, et politico-démagogique, des conseils d'enfants et de jeunes, les notions de républiques ou de villages d'enfants néveillent presque plus aucun écho et encore moins ceux de "monnaies intérieures" et de " tribunaux d'enfants". Comment expliquer cet apparent engouement dans l'aprèsguerre? Comment sont nées et ont pris corps ces différentes initiatives? D’où ontelles puisé leurs inspirations? Que sont-elles devenues? Pourquoi ont-elles aujourd'hui pratiquement disparu?

L'article de Chloé Maurel sur la Maison d'enfants de Sèvres montre à quel point ces expériences ont pu marquer leur époque, se revendiquant comme des laboratoires d'innovation pédagogique, souvent citées en modèle par les principaux théoriciens des sciences de l'éducation. Si la Maison de Sèvres a su jusqu'à aujourd'hui cultiver sa mémoire, d'autres ont sombré dans l'oubli et demanderaient aujourd'hui à être exhumées et étudiées de près pour mieux en cerner la portée.

\section{Le comité \\ de rédaction}

(1) Alfred Brauner,

docteur ès lettres, croix de

guerre 1939-1945, était

membre permanent de la

Société française

de psychopathologie de

l'expression et d'art

thérapie. Avec son épouse

Françoise, il a travaillé

au service des enfants

victimes des guerres de

1936 à 1946 puis s'est

consacré aux enfants han-

dicapés mentaux et

physiques dans les centres

de traitement éducatif

de Saint-Mandé,

sa ville natale dans le

Val-de-Marne.

(2) Alfred Brauner,

"Méthodes factices

en maison d'enfants ", in

L. Le Guillant, F. Cortez,

E. Jouhy, F. Seclet-Riou

et al., Les maisons d'enfants

(introduction de

Henri Wallon), Paris,

PUF, 1950, p. 43-52. 